\title{
Conhecimentos, atitudes e práticas dos médicos pediatras em relação à saúde bucal
}

\section{Knowledge, attitudes and practice of pediatricians in relation to oral health}

\author{
Maria do Carmo Matias FREIRE* \\ Raquel Adorno MACÊDO** \\ Welder Humberto da SILVA**
}

\begin{abstract}
FREIRE, M. C. M.; MACEDO, R. A.; SILVA, W. H. Conhecimentos, atitudes e práticas dos médicos pediatras em relação à saúde bucal. Pesq Odont Bras, v. 14, n. 1, p. 39-45, jan./mar. 2000.

A equipe de saúde tem um importante papel na educação em saúde bucal da população. O objetivo do presente estudo foi investigar o nível de conhecimento, atitudes e práticas dos médicos pediatras em relação à cárie. Um total de 96 médicos pediatras que atuam no serviço público de Goiânia - GO responderam ao questionário. Destes, 94,8\% e 96,9\% relataram que possuem informação sobre a etiologia e prevenção da cárie, respectivamente; e $88,5 \%$ examinam os dentes durante suas consultas e orientam os pais das crianças. A higiene oral e o uso de flúor foram os métodos de prevenção mais citados, enquanto o papel do açúcar na etiologia da cárie foi reconhecido por poucos médicos. A maioria concordaram que os pediatras, juntamente com os cirurgiões-dentistas, devem atuar na educação em saúde bucal dos pacientes, mas apenas $24,0 \%$ da amostra consideraram seu próprio nível de informação satisfatório. Concluiu-se que há necessidade de um maior esclarecimento aos médicos pediatras sobre o papel da dieta na cárie dental, para que informações mais corretas sejam repassadas aos pais.
\end{abstract}

UNITERMOS: Pediatria; Saúde bucal; Cárie dentária; Prevenção; Criança.

\section{INTRODUÇÃO}

Levantamentos recentes têm demonstrado que o quadro epidemiológico da cárie em pré-escolares brasileiros é preocupante, considerando-se sua manifestação precoce e a forte associação com os fatores sócio-econômicos ${ }^{9,11}$.

Medidas preventivas em geral tem se concentrado na modificação do comportamento de crianças em idade escolar, durante o processo de educação formal, o que facilita a operacionalização dos programas, mas dificulta em termos de mudança de hábitos ou atitudes já adquiridas.

Segundo BLINKHORN ${ }^{4}$ (1981), se hábitos saudáveis são ensinados em idade precoce, as ações educativas em saúde a serem implementadas mais tarde podem se basear no reforço de rotinas já estabelecidas. Desta forma, a população-alvo para os programas de educação em saúde bucal que tem como objetivo estabelecer, ao invés de modificar rotinas, são as mães de crianças jovens e até mesmo as gestantes.

No período de socialização primária da criança, ocorre a erupção dos dentes decíduos, concomitante com um rápido desenvolvimento da capacidade de comunicação que faz com que a criança seja capaz de internalizar as rotinas de comportamento que são transmitidas ${ }^{4}$.

Considerando-se que a educação em saúde bucal deveria iniciar-se nos primeiros anos de vida, torna-se importante uma abordagem integrada incluindo os meios de comunicação social e os profissionais de saúde geral e de saúde bucal, buscando conscientizar as famílias, e em especial as mães.

Os profissionais de saúde bucal são os agentes que criam as normas e, portanto, desempenham um importante papel na transmissão destas às mães, que por sua vez as interpretam e transmitem à criança ${ }^{5}$. Contudo, o cirurgião-dentista não encontra-se numa posição vantajosa em relação à cárie de mamadeira, pois geralmente a primeira consulta odontológica se dá a partir dos 3 anos, quando a doença já pode estar em estágio avançado.

\footnotetext{
* Professora Adjunta do Departamento de Ciências Estomatológicas; ** Cirurgiões-Dentistas - Faculdade de Odontologia da Universidade Federal de Goiás.
} 
FREIRE, M. C. M.; MACEDO, R. A.; SILVA, W. H. Conhecimentos, atitudes e práticas dos médicos pediatras em relação à saúde bucal. Pesq Odont Bras, v. 14, n. 1, p. 39-45, jan./mar. 2000.

A saúde bucal da criança pode ser influenciada por membros da equipe de cuidados primários de saúde, incluindo médicos generalistas ${ }^{6,10,15,21,25,26}$, pediatras $^{2,3,7,14,16,19,22,23,24,28,29}$, enfermeiros ${ }^{20}$, nutricionistas ${ }^{17}$ e agentes de saúde ${ }^{16}$, que estão numa excelente posição para discutir o problema da cárie antes da primeira visita ao dentista. SHEIHAM ${ }^{30}$ (1992) afirma que o trabalho em equipe constitui a abordagem mais adequada para a promoção de saúde bucal, utilizando-se pessoal auxiliar odontológico e pessoal não-odontológico, através da integração entre saúde bucal e saúde geral.

Médicos pediatras que acompanham o desenvolvimento da criança rotineiramente desde o nascimento estão em condições ideais para orientar os pais sobre os cuidados preventivos, incluindo hábitos dietéticos, higiene oral e uso do flúor, e também detectar precocemente sinais de cárie rampante, alertando os pais quando estes são identificados ${ }^{2,3,7,14,16,18,22,23,24,28,29}$.

Embora a importância da saúde bucal seja reconhecida na prática médica da pediatria, historicamente pouco tem sido feito pelos médicos no sentido de estabelecer e garantir linhas de educação e comunicação nesta área da saúde ${ }^{7}$. Tendo em vista o escasso número de estudos existentes na literatura, não se sabe exatamente se os médicos pediatras possuem e aplicam os conhecimentos necessários para que possam atuar na manutenção da saúde bucal de seus pacientes.

A maioria destes estudos tem se referido apenas ao uso de flúor, e poucos têm incluído questões mais amplas envolvendo a etiologia e os demais métodos de prevenção da cárie $e^{6,19,22,29}$. O objetivo do presente estudo foi investigar o nível de conhecimentos e atitudes dos médicos pediatras que atuam no serviço público de Goiânia - GO em relação à cárie. Buscou-se ainda subsidiar o desenvolvimento de programas de capacitação aos médicos pediatras para que estes possam contribuir efetivamente para a promoção de saúde bucal da população infantil.

\section{MATERIAL E MÉTODOS}

Os dados do presente estudo foram coletados em 1995 através de um questionário contendo 20 questões semi-abertas e fechadas sobre o nivel de informação, bem como as atitudes e práticas dos médicos pediatras em relação à saúde bucal dos pacientes. Parte do questionário, incluindo as questões analisadas no presente estudo, encontra-se no Quadro 1.
A população de estudo incluiu todos os médicos que atuam no serviço público municipal e estadual de saúde de Goiânia - GO, incluindo especialistas, residentes e generalistas que atuam em pediatria. Os questionários foram distribuídos aos Chefes Administrativos de cada Centro de Saúde para que fossem entregues aos profissionais e recolhidos após alguns dias. O número de questionários distribuídos foi de acordo com o número de médicos pediatras relatado por cada Secretaria, totalizando 207 médicos. Uma carta explicativa com instruções sobre o preenchimento acompanhava cada questionário, onde foi informado que as respostas seriam confidenciais, não sendo necessário identificá-lo com o nome do respondente.

As questões aqui analisadas referem-se à 8 questões sobre a etiologia e métodos de prevenção da cárie, tipo de orientação dada aos pais sobre dieta e higiene oral, realização de exame dental durante as consultas pediátricas de rotina, fontes de informação sobre saúde bucal, auto-avaliação do nivel de conhecimento sobre saúde bucal e percepção do papel do médico pediatra na prevenção da cárie nos primeiros anos de vida (Quadro 1).

Informações sobre idade, gênero e ano de graduação dos médicos pesquisados também foram obtidas. Os resultados das questões específicas sobre dieta não foram apresentados no presente estudo. O questionário não incluiu questões específicas sobre fluoretos, tendo em vista um estudo recente sobre o tema nesta mesma população ${ }^{1}$.

\section{RESULTADOS}

Dos 207 questionários entregues, 96 (46,4\%) foram respondidos e devolvidos. A amostra pesquisada foi constituída de médicos pediatras de ambos os sexos, sendo $60(62,5 \%)$ do sexo feminino e $36(37,5 \%)$ do sexo masculino, com idade entre 23 e 55 anos (média $=43,7$ anos), graduados entre 1968 e 1994, sendo a maioria (68\%) graduada no período 1970 a 1989 .

Os resultados do questionário encontram-se nas Tabelas 1 a 4. De acordo com a Tabela 1, a grande maioria dos médicos pesquisados afirmaram que possuem informação sobre os fatores etiológicos e os métodos de prevenção da cárie, repassam estas informações aos pais, examinam os dentes das crianças durante as consultas pediátricas, e orientam os pais sobre higiene bucal.

Os fatores etiológicos da cárie citados pelos médicos pediatras encontram-se na Tabela 2. O fator bacteriano foi o mais comumente associado à doença. Do total da amostra, 46,9\% apontaram fato- 
FREIRE, M. C. M.; MACEDO, R. A.; SILVA, W. H. Conhecimentos, atitudes e práticas dos médicos pediatras em relação à saúde bucal. Pesq Odont Bras, v. 14, n. 1, p. 39-45, jan./mar. 2000.

QUADRO 1 - Questionário usado na coleta de dados.

Dados pessoais:

Idade: __ Sexo: ___ Ano de Graduação:

1 - Possui informação sobre o(s) fator(es) etiológico(s) da cárie?

( ) Não. ( ) Sim. Qual (quais) é (são)?

2 - Possui informação sobre os métodos de prevenção da cárie?

( ) Não. （ ） Sim. Qual (quais) é (são)?

3 - Se respondeu sim às questões anteriores, onde recebeu esta informação?

( ) No curso de graduação.

( ) Durante a residência.

( ) Nos cursos de reciclagem promovidos pelo SUS - GO.

( ) Nos cursos de reciclagem fora do SUS - GO.

( ) Outros. Qual (quais)?

4 - Você repassa estas informações aos pais das crianças?

( ) Sim. ( ) Não.

5 - Você considera que o seu nível de informação sobre a cárie é:

( ) Satisfatório.

( ) Relativamente satisfatório.

( ) Não satisfatório.

6 - Na sua opinião, a orientação sobre a prevenção da cárie nos primeiros anos de vida é tarefa:

( ) Do cirurgião-dentista.

( ) Do médico pediatra.

( ) De ambos.

( ) Outro(s). Quem?

7 - Você examina os dentes da criança durante a consulta pediátrica de rotina?

( ) Sim. ( ) Não.

8- Você orienta os pais sobre a escovação dos dentes da criança?

( ) Sim. ( ) Não.

res bacterianos e dietéticos, e 28,1\% apenas os fatores bacterianos. $\mathrm{O}$ fator dieta, isoladamente, foi apontado por apenas $6,2 \%$ dos pesquisados. Outros fatores citados foram carência de flúor, acidez da mucosa e pouca salivação.

Em relação aos fatores bacteriológicos, 51,2\% referiram-se a má higiene oral, 31,2\% a bactérias, e $10,0 \%$ a uma associação de ambos. Apenas 4 $(5,0 \%)$ dos que referiram-se aos fatores bacterianos mencionaram os Streptococcus mutans. Os fatores dietéticos foram açúcar $(45,5 \%)$, alimentos em geral $(34,5 \%)$ e, em menor proporção, carboidratos $(7,3 \%)$ e glicose $(3,6 \%)$ (Tabela 2$)$.
TABELA 1 - Informações e práticas dos médicos pediatras em relação à saúde bucal de seus pacientes (Goiânia - GO, 1995).

\begin{tabular}{l|c|c}
\hline \multicolumn{1}{c|}{ Informações e práticas } & $\mathrm{n}$ & $\%$ \\
\hline $\begin{array}{l}\text { Possuem informação sobre os fatores etiológi- } \\
\text { cos da cárie. }\end{array}$ & 91 & 94,8 \\
\hline $\begin{array}{l}\text { Possuem informação sobre os métodos de pre- } \\
\text { venção da cárie. }\end{array}$ & 93 & 96,9 \\
\hline Repassam as informações aos pais das crianças. & 86 & 89,6 \\
\hline $\begin{array}{l}\text { Examinam os dentes dos pacientes durante a } \\
\text { consulta pediátrica. }\end{array}$ & 85 & 88,5 \\
\hline $\begin{array}{l}\text { Orientam os pais sobre a escovação dos dentes } \\
\text { da criança. }\end{array}$ & 86 & 89,6 \\
\hline \hline
\end{tabular}

A higiene oral foi também o método de prevenção mais freqüentemente apontado pela maioria dos médicos pediatras, como pode ser observado na Tabela 3. A combinação mais comum foi a higiene oral e o uso de flúor, sendo mencionada por $27,1 \%$ da amostra, seguida pela higiene oral, uso do flúor e controle da dieta $(16,7 \%)$ e higiene oral e controle da dieta $(22,9 \%)$. Outras medidas preventivas relatadas foram selantes, visitas ao cirurgião-dentista, uso de cálcio e evitar contatos orais com a criança.

Observa-se na Tabela 4 que apenas $38,5 \%$ dos pesquisados relataram que receberam informações sobre saúde bucal durante o curso de graduação em medicina, enquanto um percentual ainda menor $(24,0 \%)$ receberam este conteúdo durante a residência em pediatria. Outras fontes de informação apontadas foram principalmente cursos de reciclagem fora do SUS - GO $(28,1 \%)$ e publicações da área $(14,6 \%)$.

Quanto à auto-avaliação do nível de informação sobre saúde bucal, $24,0 \%$ dos médicos o consideraram satisfatório, 59,4\% relativamente satisfatório e $16,7 \%$ não satisfatório.

$\mathrm{Na}$ opinião dos pesquisados, os profissionais de saúde responsáveis pela prevenção da cárie nos primeiros anos de vida são o cirurgião-dentista e o médico, atuando de forma integrada $(67,7 \%)$, enquanto $29,2 \%$ consideraram que esta é uma responsabilidade apenas do médico e $3,1 \%$ apenas do cirurgião-dentista.

\section{DISCUSSÃO E CONCLUSÕES}

A taxa de resposta obtida neste estudo foi inferior aos relatados na maioria dos estudos anterio- 
FREIRE, M. C. M.; MACEDO, R. A.; SILVA, W. H. Conhecimentos, atitudes e práticas dos médicos pediatras em relação à saúde bucal. Pesq Odont Bras, v. 14, n. 1, p. 39-45, jan./mar. 2000.

TABELA 2 - Fatores etiológicos da cárie de acordo com os médicos pediatras (Goiânia - GO, 1995).

\begin{tabular}{l|c|c}
\hline \hline \multicolumn{1}{c|}{ Fatores etiológicos $(\mathrm{n}=96)$} & $\mathrm{n}$ & $\%$ \\
\hline Fatores bacterianos e dietéticos & 45 & 46,9 \\
\hline Fatores bacterianos & 27 & 28,1 \\
\hline Fatores dietéticos & 06 & 6,2 \\
\hline Fatores bacterianos, dieta e carência de flúor & 04 & 4,2 \\
\hline Fatores bacterianos e carência de flúor & 03 & 3,1 \\
\hline Acidez da mucosa & 01 & 1,0 \\
\hline Fatores bacterianos e pouca salivação & 01 & 1,0 \\
\hline Não responderam & 09 & 9,4 \\
\hline \multicolumn{1}{c|}{ Fatores bacterianos (n=80) } & $\mathrm{n}$ & $\%$ \\
\hline Má higiene oral & 41 & 51,2 \\
\hline Bactérias & 25 & 31,2 \\
\hline Má higiene oral e bactérias & 08 & 10,0 \\
\hline Streptococcus mutans & 04 & 5,0 \\
\hline Streptococcus & 01 & 1,2 \\
\hline Microorganismos & 01 & 1,2 \\
\hline \multicolumn{1}{c|}{ Fatores dietéticos (n=55) } & $\mathrm{n}$ & $\%$ \\
\hline Açúcar & 25 & 45,5 \\
\hline Alimentos & 19 & 34,5 \\
\hline Carboidratos & 04 & 7,3 \\
\hline Doces & 03 & 5,5 \\
\hline Glicose & 02 & 3,6 \\
\hline Desnutrição e dieta & 01 & 1,8 \\
\hline Desnutrição & & 1,8 \\
\hline \hline
\end{tabular}

res $^{6,10,19}$. Entretanto, o número total de profissionais parece ter sido superestimado, pois um número considerável de médicos atuam nas duas instituições e, portanto, foram contados duas vezes. A falta de tempo relatada pelos profissionais e as dificuldades encontradas na distribuição dos questionários também parecem ter contribuído, demonstrando algumas das dificuldades ao se realizar este tipo de estudo no atual sistema de saúde pública. Os resultados aqui observados demonstram que os médicos pediatras que atuam no serviço público de Goiânia - GO apresentam atitudes e práticas positivas em relação à saúde bucal de
TABELA 3 - Métodos de prevenção da cárie de acordo com os médicos pediatras (Goiânia - GO, 1995).

\begin{tabular}{l|c|c}
\hline \multicolumn{1}{c|}{ Métodos de prevenção } & $\mathrm{n}$ & $\%$ \\
\hline Higiene oral e flúor & 26 & 27,1 \\
\hline Higiene oral, flúor e controle da dieta & 16 & 16,7 \\
\hline Higiene oral e controle da dieta & 22 & 22,9 \\
\hline Higiene oral & 06 & 6,2 \\
\hline Higiene oral, flúor e selante & 04 & 4,2 \\
\hline Flúor & 03 & 3,1 \\
\hline Higiene oral, controle da dieta, flúor e selante & 02 & 2,1 \\
\hline $\begin{array}{l}\text { Higiene oral, flúor e visitas ao cirur- } \\
\text { gião-dentista }\end{array}$ & 02 & 2,1 \\
\hline $\begin{array}{l}\text { Higiene oral, controle da dieta e visitas ao ci- } \\
\text { rurgião-dentista }\end{array}$ & 02 & 2,1 \\
\hline $\begin{array}{l}\text { Higiene oral, controle da dieta, flúor e visitas } \\
\text { ao cirurgião-dentista }\end{array}$ & 01 & 1,0 \\
\hline Flúor e cálcio & 01 & 1,0 \\
\hline Controle da dieta e flúor & 01 & 1,0 \\
\hline Controle da dieta & 01 & 1,0 \\
\hline Higiene oral e evitar contatos orais & 01 & 1,0 \\
\hline Não responderam & 08 & 8,3 \\
\hline \hline
\end{tabular}

seus pacientes, coincidindo com os achados de outros autores sobre pediatras ${ }^{18,20,29}$ e sobre médicos generalistas $^{6,10}$.

$\mathrm{O}$ alto percentual de médicos que relataram examinar os dentes das crianças nas consultas rotineiras $(88,5 \%)$ está de acordo com resultados de estudos anteriores ${ }^{22,29}$. SCHULTE et al. $^{29}$ (1992) revelaram que $95,0 \%$ dos pediatras realizam este exame antes da idade de 2 anos, e quando questionados sobre quais os profissionais de saúde deveriam fazê-lo antes dos 3 anos, 70,0\% indicaram o dentista e 85,0\% consideraram também o médico.

A Comissão de Padronização dos Cuidados de Saúde da Criança da Academia Americana de Pediatria recomenda inspeção da boca, dentes e gengivas a cada consulta pediátrica ${ }^{25}$. No presente estudo, um elevado número de médicos relataram que orientam os pais sobre a prevenção da cárie $(89,6 \%)$ e sobre a escovação dos dentes da criança $(89,6 \%)$, em consonância com estudos anteriores. De acordo com GIFT et al. ${ }^{10}$ (1984) 48,0\% dos médicos orientam a maioria dos seus pacientes meno- 
FREIRE, M. C. M.; MACEDO, R. A.; SILVA, W. H. Conhecimentos, atitudes e práticas dos médicos pediatras em relação à saúde bucal. Pesq Odont Bras, v. 14, n. 1, p. 39-45, jan./mar. 2000.

TABELA 4 - Fontes de informação dos médicos pediatras sobre saúde bucal (Goiânia - GO, 1995).

\begin{tabular}{l|c|c}
\hline \hline \multicolumn{1}{c|}{ Fontes de informação } & $\mathrm{n}$ & $\%$ \\
\hline Curso de graduação & 37 & 38,5 \\
\hline Cursos de reciclagem fora do SUS - GO** & 27 & 28,1 \\
\hline Residência em pediatria & 23 & 24,0 \\
\hline Publicações & 14 & 14,6 \\
\hline Cirurgiões-dentistas & 10 & 10,4 \\
\hline Cursos de reciclagem promovidos pelo & 08 & 8,3 \\
SUS - GO** & 08 & 8,3 \\
\hline Outros & 08 \\
\hline \hline
\end{tabular}

*Respostas múltiplas.

**SUS-GO: Sistema Único de Saúde de Goiás.

res de 18 anos sobre a cárie, enquanto a grande maioria orientam no mínimo alguns deles. MARANHÃO; GRINFELD ${ }^{22}$ (1993) relataram que a grande maioria dos pediatras orientam as mães quanto à limpeza da boca da criança $(92,0 \%)$, recomendam sobre a compra de escova e creme dentais $(82,0 \%)$ e orientam sobre a escovação dos dentes $(56,0 \%)$, enquanto apenas $24,0 \%$ fazem demonstração da técnica às mães. Dos pediatras pesquisados por KORANYI et al. ${ }^{19}$ (1991), 91,3\% relataram discutir escovação dental com os pais e a idade média para introdução desta prática foi 18,25 meses.

As informações apresentadas pelos médicos pediatras sobre a etiologia e prevenção da cárie não estão totalmente consistentes com a evidência científica disponivel até o momento. Em relação à etiologia da cárie, verificou-se que os médicos tem conhecimento sobre os fatores biológicos, mas nenhum mencionou os determinantes sociais e econômicos que influenciam na instalação e desenvolvimento da doença ${ }^{8,27}$.

Os fatores bacterianos foram fortemente relacionados à cárie. O papel da dieta, por outro lado, não foi reconhecido pela grande maioria dos pediatras. Além disso, grande parte dos que citaram a dieta referiram-se aos alimentos em geral e, dentre os que citaram o açúcar (apenas $45,5 \%$ ), nenhum mencionou a sacarose. No estudo realizado por DIU; GELBIER ${ }^{6}$ (1987) entre médicos generalistas de Londres, embora a má higiene oral e a placa bacteriana tenham sido freqüentemente associadas à cárie, a freqüência diária de consumo de açúcar foi o principal fator.
No presente estudo, os meios de prevenção da cárie mais citados foram a higiene oral e o uso de flúor, e menos da metade dos pesquisados mencionaram a dieta. Resultados semelhantes foram relatados por GIFT et al. ${ }^{10}$ (1984). Assim como no presente estudo, apenas $47,4 \%$ dos pesquisados citaram o aconselhamento nutricional e dietético. DIU; GELBIER ${ }^{6}$ (1987), encontraram resultados semelhantes em relação à higiene oral e flúor, embora a maioria tenha mencionado também o controle da dieta (92\%).

AQUINO $^{1}$ (1995) demonstrou que a maioria dos médicos pediatras de Goiânia - GO prescrevem suplementação de flúor aos pacientes residentes em regiões fluoretadas, revelando pouco conhecimento sobre os efeitos da combinação de métodos.

$\mathrm{O}$ alto percentual de médicos que relacionaram a higiene oral à cárie demonstra que a maioria destes profissionais, assim como os próprios cirurgiões-dentistas, encontram-se desinformados sobre o papel relativo deste método no controle da doença. Estudos têm evidenciado que escovação e outras medidas de higiene oral sem a influência do flúor geralmente possuem pequeno efeito comparado com o papel da dieta ${ }^{31}$.

É interessante observar que apenas $5,2 \%$ dos médicos indicaram visitas ao dentista como meio de prevenção da cárie, contrastando com 61,0\% dos pesquisados por DIU; GELBIER ${ }^{6}$ (1987). Este dado sugere que os médicos pediatras de Goiânia tem valorizado os métodos de prevenção que independem da atuação clínica direta do cirurgião-dentista.

Embora a principal fonte de informação relatada pelos médicos pediatras tenha sido o curso de graduação, este foi apontado por apenas 38,5\% da amostra. Este dado sugere que, embora a cárie dental seja uma das doenças mais comuns na infância, pouca ênfase tem sido dada a esta área dentro dos currículos de medicina. Em concordância com o presente estudo, SCHULTE et al. ${ }^{29}$ (1992) relataram que as principais fontes primárias de informação sobre o diagnóstico da cárie entre pediatras foram a própria experiência clínica pediátrica $(46 \%)$, a residência em pediatria $(30 \%)$ e, em menor proporção, a Faculdade de medicina (17\%).

Apesar da grande maioria dos médicos terem afirmado que possuem conhecimento sobre a etiologia e prevenção da cárie e que repassam estas informações aos pais, apenas $24,0 \%$ destes consideraram seu nivel de informação satisfatório. Este resultado sugere um elevado grau de insegurança 
FREIRE, M. C. M.; MACEDO, R. A.; SILVA, W. H. Conhecimentos, atitudes e práticas dos médicos pediatras em relação à saúde bucal. Pesq Odont Bras, v. 14, n. 1, p. 39-45, jan./mar. 2000.

por parte destes profissionais quanto ao tipo de orientação que é dada aos pais, provavelmente devido à fragmentação e pouca consistência das informações recebidas. Nota-se na Tabela 4 que apenas $8,3 \%$ dos respondentes afirmaram que receberam algum tipo de informação dentro do próprio serviço.

Não obstante o baixo percentual de médicos que consideraram satisfatório o seu nível de informação, a maioria dos pesquisados concordaram que os médicos pediatras são os profissionais de saúde responsáveis pela prevenção da cárie nos primeiros anos de vida da criança. Chama a atenção o fato de que $29,2 \%$ afirmaram que esta deve ser responsabilidade exclusiva do médico, contrastando com apenas 3,1\% que referiram-se apenas ao cirurgião-dentista. Estes resultados sugerem que os médicos pediatras estão predispostos a atuar mais ativamente em saúde bucal, reconhecendo a importância da abordagem multidisciplinar nos cuidados primários de saúde.

Por outro lado, alguns estudos têm revelado uma discrepância entre as atitudes e práticas manifestadas pelos médicos e o relato das mães sobre as orientações sobre saúde bucal recebidas através destes profissionais. De acordo com KORANYI et al. ${ }^{19}$ (1991), 94,0\% dos pediatras relataram discutir o desmame da mamadeira com os pais, desencorajando ativamente a mamadeira noturna, principalmente devido ao risco de cárie. No entanto, apenas $11,0 \%$ das mães que freqüentavam uma clínica médica consideraram o médico da criança como a fonte primária deste tipo de informação. MARANHÃO; GRINFELD ${ }^{22}$ (1993) também ob- servaram desencontro de informações entre pediatras e mães em relação à prescrição de flúor, higiene oral e encaminhamento da criança ao odontopediatra.

As principais barreiras encontradas pelos médicos em relação à educação em saúde na prática clínica, apesar do seu alto grau de motivação, têm sido a falta de tempo durante as consultas e as dificuldades de comunicação profissional-paciente ${ }^{32}$. Embora seja dificil estabelecer o grau de importância do fator tempo como barreira para a educação do paciente, este deve ser considerado no planejamento dos programas educativos.

Os dados do presente estudo sugerem que há interesse por parte dos médicos pediatras em atuar na educação em saúde bucal dos seus pacientes, sendo necessário um maior esclarecimento sobre o papel da higiene oral e da dieta na prevenção da cárie, para que informações mais corretas sejam repassadas aos pais. Considerando-se a alta prevalência da doença entre crianças menores de 6 anos de idade de nível sócio-econômico mais bai$\mathrm{xo}^{9}$, uma abordagem multidisciplinar, envolvendo toda a equipe de saúde, deve ser amplamente considerada.

\section{AGRADECIMENTOS}

Nossos agradecimentos especiais à Dra. Marta, Chefe da Coordenadoria da Rede Básica da Secretaria Municipal de Saúde de Goiânia - GO, aos Chefes Administrativos dos Centros de Saúde e a todos os médicos que dedicaram uma parte do seu tempo ao preenchimento dos questionários.

FREIRE, M. C. M.; MACEDO, R. A.; SILVA, W. H. Knowledge, attitudes and practice of pediatricians in relation to oral health. Pesq Odont Bras, v. 14, n. 1, p. 39-45, jan./mar. 2000.

Primary health workers have an important role in oral health promotion. The aim of this study was to investigate knowledge, attitudes and practice of pediatricians regarding dental caries. A total of 96 pediatricians working in the public health service of Goiânia - GO, Brazil, answered the questionnaire. From these, 94.8\% and 96.9\% reported that they were aware of dental caries etiology and prevention, respectively; and 89.6\% examined children's teeth in their consultations and gave advice to the parents. Oral hygiene and fluoride were the most commonly mentioned methods of prevention; only a few pediatricians were aware of the role of sugars in the etiology of dental caries. The majority agreed that pediatricians as well as dentists should play a role in oral health education of patients, but only $24.0 \%$ said that their own level of information was satisfactory. Pediatricians need to be better informed about the role of sugars in dental caries, so that more correct information can be given to the parents.

UNITERMS: Pediatrics; Oral health; Dental caries; Prevention; Child. 
FREIRE, M. C. M.; MACEDO, R. A.; SILVA, W. H. Conhecimentos, atitudes e práticas dos médicos pediatras em relação à saúde bucal. Pesq Odont Bras, v. 14, n. 1, p. 39-45, jan./mar. 2000.

\section{REFERÊNCIAS BIBLIOGRÁFICAS}

1. AQUino, M. A. T. Anápolis, 1995. Suplementação de flúor: Uma necessidade ou um risco. (Monografia de especialização, F. O. João Prudente, Associação Educativa Evangélica).

2. BARREIRO-DAVINA, A.; BRAVO-MARCOS, V. El pediatra y la salud bucal. An Esp Pediatr, v. 26, n. 6, p. 463-466, 1987.

3. BERNICK, S. M. What the pediatrician should know about children's teeth. IV. Baby-Bottle syndrome. Clin Pediatr, v. 10, n. 4, p. 243-244, 1971.

4. BLINKHORN, A. S. Dentists and their potential to influence mothers of pre-school children. J Inst Health Educ, v. 6 , n. 1, p. 3-6, 1978.

5. BLINKHORN, A. S. Dental preventive advice for pregnant and nursing mothers - Sociological implications. Int Dent J, v. 31, p. 14-22, 1981.

6. DIU, S.; GELBIER, S. Dental awareness and attitudes of general medical practitioners. Community Dent Health, v. 4, p. 437-444, 1987.

7. ELVEY, S. M.; HEWIE, S. P. The pediatrician's dental evaluation. Pediatr Clin North Am, v. 29, n. 3, p. 761-769, 1982.

8. ERIKSEN, H. M.; BJERTNESS, E. Concepts of health and disease and caries prediction: A literature review. Scand J Dent Res, v. 99, p. 476-483, 1991.

9. FREIRE, M. C. M.; MELO, R. B.; SILVA, S. A. Dental caries prevalence in relation to socioeconomic status of nursery school children in Goiânia - GO, Brazil. Community Dent Oral Epidemiol, v. 24, p. 357-371, 1996.

10. GIFT, G.; MILTON, B.; WALSH, V. Physicians and caries prevention: Results of a Physician survey on preventive dental services. J Am Med Assoc, v. 252, n. 11, p. 1447-1448, 1984.

11. GRANER, R. O. M.; RONTANI, R. M. P.; GAVIÃO, M. B. D.; BOCCATO, H. C. A. R. Caries prevalence in 6-36-month-old Brazilian children. Community Dent Health, v. 13, p. 96-98, 1996.

12. GREENE, J. C.; LOUIE, R.; WYCOFF, S. J. Preventive dentistry. I. Dental caries. J Am Med Assoc, v. 262, n. 24, p. 3459-3463, 1989.

13. GREENE, J. C.; LOUIE, R.; WYCOFF, S. J. Preventive dentistry. II. Periodontal diseases, malocclusion, trauma, and oral cancer. J Am Med Assoc, v. 263, n. 3, p. 421-425, 1990.

14. HERRMANN, H. J.; ROBERTS, M. W. Preventive dental care: the role of the pediatrician. Pediatrics, v. 80 , n. 1 , p. 107-110, 1987.

15. HESS, J. W.; MARGOLIS, F. J. The physician's role in caries prevention. Am Fam Physician, v. 24. n. 4, p. 171-173, 1981.

16. JOHNSEN, D. C. The role of the pediatrician in identifying and treating dental caries. Pediatr Clin North Am, v. 38, n. 5, p. 1173-1181, 1991.

17. JOHNSEN, D.; NOWJACK-RAYMER, R. Baby bottle tooth decay: issues, assessment, and an opportunity for the nutritionists. J Am Diet Assoc, v. 89, p. 1112-1116, 1989.

18. KING, J. M. Behaviour of mothers and babies which may influence future dental health. Londres, 1976. $156 \mathrm{p}$. Tese (Mestrado) - The London Hospital Medical College Dental School.

19. KORANYI, K.; RASNAKE, L. K.; TARNOWSKI, K. J. Nursing bottle weaning and prevention of dental caries: a survey of pediatricians. Pediatr Dent, v. 13, n. 1, p. 32-34, 1991.

20. LANE, B. J.; SELLEN, V. Bottle caries: a nursing responsibility. Can J Public Health, v. 77, p. 128-130, 1986.

21. LOKSHIN, M. F. Preventive oral health care: a review for family physicians. Am Fam Physician, v. 50, n. 8, p. 1677-1684, 1994.

22. MARANHÃO, M. C. A.; GRINFELD, S. Pediatra $\mathbf{x}$ Odontopediatra - Orientação à saúde bucal da criança. Prêmio Kolynos, 1993.

23. MILLER, R. E.; ROSENSTEIN, D. Children's dental health: Overview for the physician. Pediatr Clin North Am, v. 29. n. 3, p. 434-435, 1982.

24. MULLER-GIAMARCHI, M.; JASMIN, J. R. Le syndrome du biberon. Pédiatrie-(Bucur)., v. 45, n. 7-8, p. 485-489, 1990.

25. NIRSCHL, R. F.; KRONMILLER, J. E. Evaluating oral health needs in preschool children. Clin Pediatr Phila, v. 25, n. 7, p. 358-362, 1986.

26. PINKERTON, R. E.; TINANOFF, N.; WILLMS, J. L.; RAMANAN, C. Preventing dental caries. Am Fam Physician, v. 23, n. 3, p. 167-170, 1981

27. REISINE, S.; LITT, M. Social and psychological theories and their use for dental practice. Int Dent J, v. 43, n. 279-287, 1993.

28. RIPA, L. W. The role of the pediatrician in dental caries detection and prevention. Pediatrics, v. 54, n. 2, p. 176-182, 1974

29. SCHUlTE, J. R.; DRUYAN, M. E.; HAGEN, J. C. Early childhood tooth decay: pediatric interventions. Clin Pediatra (Phila), v. 31, n. 12, p. 727-730, 1992.

30. SHEIHAM, A. The role of the dental team in promoting dental health and general health through oral health. Int Dent J, v. 42, p. 223-228, 1992.

31. SUTCLIFFE, P. Oral cleanliness and dental caries. In: MURRAY, J. J. The prevention of dental disease. Oxford : Oxford University Press, 1983. p. 201-217.

32. TAPPER-JONES, L.; SMAIL, S. A.; PILL, R.; DAVIS, R. H. Doctor's attitudes towards patient education in the primary care consultation. Health Educ J, v. 49, n. 2, 1990.
Recebido para publicação em 18/06/99

Enviado para reformulação em 04/10/99 Aceito para publicação em 13/12/99 